\title{
A review of 2975 consecutive operations by one surgeon in an accredited outpatient plastic surgicentre: A Canadian experience
}

\author{
Leslie R Chasmar MD FRCSC
}

\begin{abstract}
LR Chasmar. A review of 2975 consecutive operations by one surgeon in an accredited outpatient plastic surgicentre: A Canadian experience. Can J Plast Surg 2005;13(4):188-190.

The present paper constitutes a retrospective review of 2975 consecutive operations performed by the author, one of the three owners of the Saskatoon Plastic Surgicentre. The unit opened in 1987; therefore, the study spans 17 years. Patients are not kept overnight, and the Surgicentre is approved and equipped as a level C facility for general anesthesia. Only patients who score 1 or 2 according to the American Association of Anesthesiologists are treated. Only certified anesthesiologists are used. Of the patients with postoperative complications, only two required transfer to a hospital. One developed a pneumothorax, which was treated on arrival at the intensive care unit with no sequelae. The other collapsed following facelift surgery. She was transferred to University of Saskatchewan hospital and died later that evening with a massive pulmonary embolus. In a properly established outpatient centre, a large number of patients can be safely treated with very few complications. However, despite placing patient safety as the first consideration and adhering strictly to the highest standards, death can occur.
\end{abstract}

Key Words: Ambulatory surgery; Retrospective review; Surgical complications

\author{
Analyse de 2975 opérations consécutives \\ exécutées par un chirurgien dans un centre de \\ chirurgie plastique ambulatoire accrédité : \\ Une expérience canadienne
}

\begin{abstract}
Le présent article constitue une analyse rétrospective de 2975 opérations consécutives exécutées par l'auteur, qui est l'un des trois propriétaires du Saskatoon Plastic Surgicentre. L'unité a ouvert ses portes en 1987. Par conséquent, l'étude s'étale sur 17 ans. Les patients ne sont pas hospitalisés pour la nuit, et le centre est approuvé et équipé comme un centre de niveau $\mathrm{C}$ pour l'anesthésie générale. Seuls les patients qui obtiennent un indice de 1 ou 2 selon l'American Association of Anesthesiologists sont traités. On a toujours fait appel à des anesthésistes certifiés. Parmi les patients qui ont souffert de complications postopératoires, seulement deux ont dû être transférés à l'hôpital. Un a développé un pneumothorax qui a été traité à l'arrivée à l'unité de soins intensifs et qui n'a laissé aucunes séquelles. L'autre a fait un collapsus après une rhytidectomie. Elle a été transférée à l'hôpital de l'université de la Saskatchewan et est décédée en soirée par suite d'une embolie pulmonaire massive. Dans un centre ambulatoire bien établi, un grand nombre de patients peut être traité en toute sécurité et souffrir de très peu de complications. Cependant, même si la sécurité des patients est placée en priorité et que les normes les plus élevées sont rigoureusement respectées, des décès peuvent survenir.
\end{abstract}

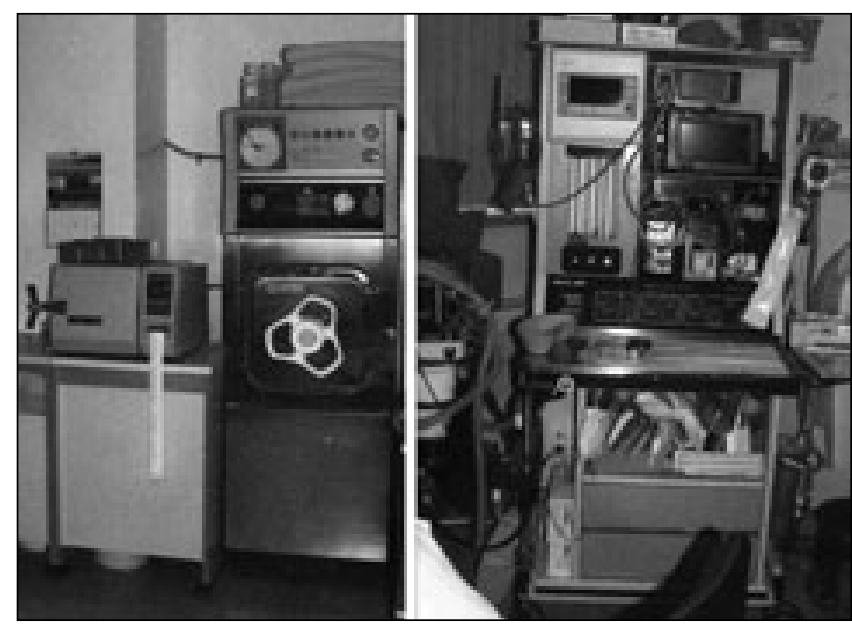

Figure 1) Views of two areas of the Saskatoon Plastic Surgicentre

\section{THE PATIENTS}

A breakdown of the types of patients treated is listed in Table 1 . Seventy-eight per cent of the patients fall into the six most common cosmetic procedure categories carried out in North America today. 
TABLE 1

Procedures performed at the Saskatoon Plastic Surgicentre during 2975 consecutive operations*

\begin{tabular}{lr}
\hline Procedure & n \\
\hline Group 1 (78\% of total) & 427 \\
Face lift & 320 \\
Coronal & 434 \\
Blepharoplasty & 393 \\
Liposuction & 345 \\
Rhinoplasty & 392 \\
Breast augmentation & \\
Group 2 (9\% of total) & 60 \\
Mastopexy & 29 \\
Capsulotomy & 46 \\
Pocket adjustment & 98 \\
Change/removal of implants & 5 \\
Breast reduction & 34 \\
Abdominoplasty & \\
Group 3 (14.5\% of total) & 9 \\
Gynecomastia & 26 \\
Facial implants & 136 \\
Laser resurfacing & 82 \\
Laser lids - Tranconjunctival & 67 \\
Dermabrasion & 7 \\
Endoscopic coronal & 105 \\
Miscellaneous (otoplasty, etc) & \\
\hline & \\
M & \\
\hline
\end{tabular}

*Numbers do not add up to 2975 because some patients had more than one procedure performed during a single session

TABLE 2

\section{Postoperative complications}

\begin{tabular}{lr}
\hline & $\mathbf{n}(\%)$ \\
\hline Breasts & $29(8.25)$ \\
Capsulotomy & $6(0.75)$ \\
Hematoma & $1(0.30)$ \\
Infection with implant removal & \\
Combined facelift and coronal lift (3.68\% of total complications) \\
Nerve injury* \\
$\quad 3(0.70)$ \\
Great auricular & $17(2.40)$ \\
Depressor angulioris & $4(0.96)$ \\
Levator labii superioris & $1(0.24)$ \\
Depressor labii inferioris & $3(0.72)$ \\
Facelift & \\
Hematoma & $3(0.70)$ \\
Large postauricular slough (bilateral) & $1(0.24)$ \\
\hline
\end{tabular}

${ }^{*}$ All recovered

\section{COMPLICATIONS}

Postoperative complications are listed in Table 2. Capsulotomy of the breasts included release for a tight capsule as well as correction of malposition or reduction of too large a pocket. While all nerve injuries recovered, and most recovered in three or four months, weakness of the depressor labii inferioris (Figure 2) was especially slow to recover. Two of the three injuries to this muscle took almost 12 months to recover.

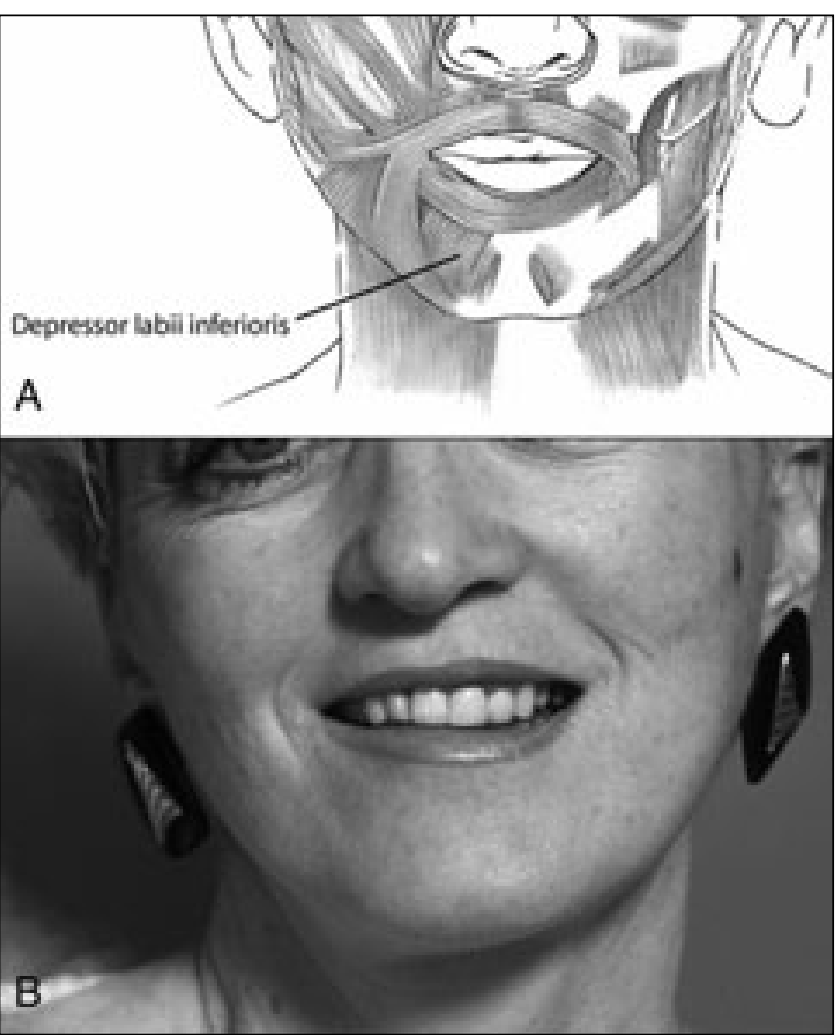

Figure 2) Injury to the depressor labii inferioris (A) during a combined face-and coronal lift resulted in unilateral weakness (B). The patient experienced a full recovery

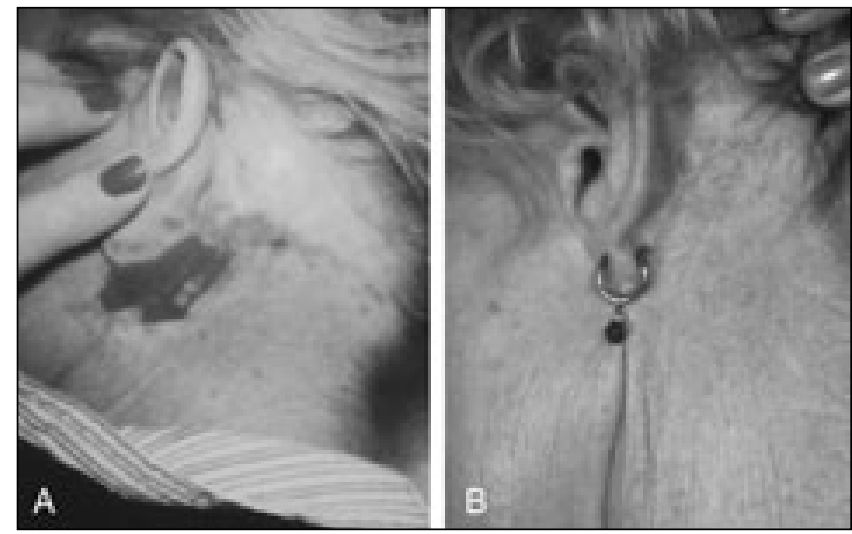

Figure 3) Large, bilateral postauricular slough (A) as a result of a facelift. The patient was fully healed after four months (B)

Large, bilateral postauricular sloughs that developed following a facelift took four months to heal (Figure 3). One patient who had a full face laser procedure developed bleaching 11 months after surgery and, in addition, tracks from the laser on both cheeks, which were quite distressing and difficult to reduce (Figure 4).

Two patients were transferred to hospital from the Surgicentre during the time of the study. One developed a pneumothorax, which was identified in the recovery room shortly after surgery. The patient was reintubated and transferred to the intensive care unit of a local hospital, where a tube was inserted.

The second patient developed complications following a facelift. She was up and walking around, chatting to the nurses, 

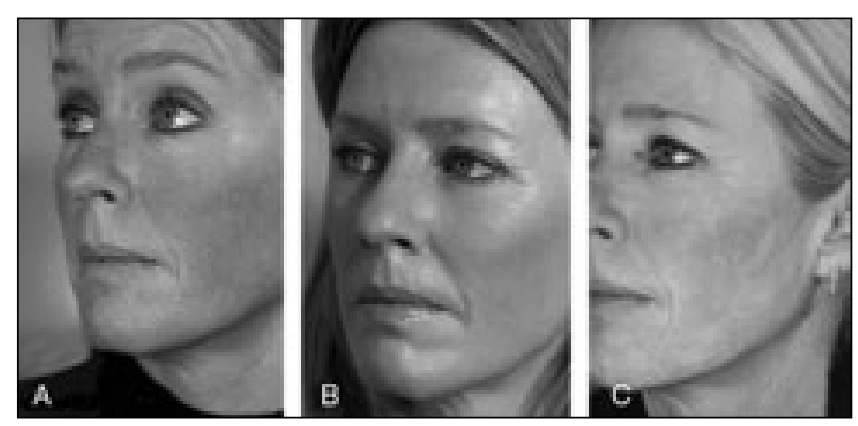

Figure 4) Postoperative bleaching following full face laser surgery. A Before laser resurfacing; B Three months after laser resurfacing; C Eleven months after laser resurfacing

when she asked to use the bathroom before getting dressed. The nurses heard a thump and found that she had fallen off the toilet and was unresponsive. The patient was reintubated, an intravenous line was started, and she was transferred to the intensive care unit at the University of Saskatchewan hospital. Despite every effort, the patient died later the same evening. Autopsy showed a massive pulmonary embolus. This patient had no history of thromboembolic episodes. She was assessed preoperatively by a cardiologist. She was not polycythemic. The anaesthesiologist had administered intravenous sedation and oxygen by nasal catheter. The local infiltration was bupivacaine $0.5 \%$ and lidocaine $0.5 \%$, both with 1:200,000 adrenaline.

No legal action has been taken nor have there been any threats of legal action with respect to any of these patients.

\section{CONCLUSION}

The aim of the present paper was twofold. Complications in an accredited facility are rare and, to date, retrospective studies with more participants than present here have almost, without exception, had no deaths (2-4). It is important to know that death can occur despite employing the highest standards of patient care.

ACKNOWLEDGEMENTS: The author thanks Wendy GoreHickman MD FRCPC, anaesthesiologist, for scheduling a specialist anaesthesiologist to our Surgicentre, consistenyly and without fail, over the years. Also, the author expresses his grateful appreciation to Ms Bev Singer, our head nurse, for her invaluable help with chart review, and to Ms Dixie Howard for manuscript preparation.

\section{REFRENCES}

1. Byrd HS, Barton FE, Orenstein HH, et al. Safety and efficacy in an accredited outpatient plastic surgery facility: A review of 5316 consecutive cases. Plast Reconstr Surg 2003;112:636-41.

2. Natof HE. Complications associated with ambulatory surgery. JAMA 1980;244:1116-8.

3. Hoefflin SM, Bornstein JB, Gordon M. General anesthesia in an office-based plastic surgical facility: A report on more than 23,000 consecutive office-based procedures under general anesthesia with no significant anesthetic complications. Plast Reconstr Surg 2001;107:243-51.

4. Warner MA, Shields SE, Chute CG. Major morbidity and mortality within 1 month of ambulatory surgery and anaesthesia. JAMA 1993;270:1437-41. 